\title{
Correspondence
}

\section{Postoperative epidural analgesia}

To the Editor:

The use of "multi-modal or balanced analgesia" to improve postoperative pain relief has received major interest in recent years. However, the optimal composition and dosage regimen for such combinations have not been settled. Therefore, Badner et al. should be congratulated for providing additional information in this field, based upon double-blind randomized studies. ${ }^{1,2}$

In a recent study ${ }^{2}$ Badner and Komar concluded that additional bupivacaine $0.1 \%$, with an average infusion rate of $7-9 \mathrm{ml} \cdot \mathrm{hr}^{-1}$ did not improve analgesia when combined with a continuous epidural fentanyl infusion at about $70-90 \mu \mathrm{g} \cdot \mathrm{hr}^{-1}$ in patients undergoing major abdominal or thoracic surgery. However, we would like to dispute their conclusion, since the study has several flaws in its design: (1) in their study Badner and Komar used an epidural catheter inserted between $\mathrm{T}_{11-12} / \mathrm{L}_{4-5}$ despite the fact that almost all patients had major abdominal or thoracic procedures. Although we will agree that the site of insertion of the catheter may have less, if any, importance regarding epidural opioid administration, it is well established that epidural local anaesthetics have to be administered at or very near the dermatomal level of the surgical incision. Therefore, it is not unexpected that the small additional bupivacaine dose did not improve analgesia. (2) Patients received intraoperative epidural anaesthesia with local anaesthetics at the discretion of the anaesthetists, but no information is given on how many patients or in which group. This is insufficient, since a preemptive epidural blockade may have had influence on postoperative pain, although we do not think such an effect to be major. (3) Finally, in order to detect differences in analgesic potency of various regimens it is insufficient to assess pain only at rest, since differential analgesic effects have been demonstrated by adding a small dose bupivacaine to epidural opioids, ${ }^{3,4}$ a difference which only appeared when pain also was assessed during function i.e., cough and mobilization.

For these reasons, the negative results of the study by Badner and Komar ${ }^{2}$ should not be used as an argument for not using the combination of epidural bupivacaine and opioids. We agree that further studies to clarify the optimal dosage regimens in different operations are required.
Henry Kehlet MD PhD

Surgical Gastroent. dept. 235

Jørgen Dahl MD

Dept. of Anesthesiology

Hvidovre University Hospital

DK-2650 Hvidovre

Denmark

\section{REFERENCES}

1 Badner NH, Reimer EJ, Komar WE Moote CA. Low dose bupivacaine does not improve postoperative epidural fentanyl and analgesia in orthopaedic patients. Anesth Analg 1991; 72: 337-41.

2 Badner NH, Komar WE. Bupivacaine $0.1 \%$ does not improve postoperative epidural fentanyl analgesia after abdominal or thoracic surgery. Can J Anaesth 1992; 39: 330-6.

3 Dahl JB, Rosenberg J, Hansen BL, Hjorts/ N-C, Kehlet $H$. Differential analgesic effects of low dose epidural morphine and morphine-bupivacaine at rest and during mobilization after major abdominal surgery. Anesth Analg 1992; 74: $362-5$

4 Mourisse JC, Hasenbos MAWM, Gielen MJM, Moll JE, Cromheecke GJE. Epidural bupivacaine, sufentanil or the combination for postthoracotomy pain. Acta Anaesthesiol Scand 1992; 36: 70-4.

\section{$R E P L Y$}

We thank Drs. Kehlet and Dahl for their interest in our work. ${ }^{1,2}$ From our results we did not intend that one should avoid the addition of bupivacaine with opioids altogether when used for postoperative analgesia, but simply that the $0.1 \%$ concentration of bupivacaine is insufficient.

In addressing their specific concerns, though the epidural location was not optimal for all the patients in the abdominal surgery study, ${ }^{2}$ the use of lumbar catheters for orthopaedic patients is clearly appropriate, ${ }^{2}$ and the same negative conclusion also resulted when using $0.1 \%$ bupivacaine. We did not initially report the amounts of intraoperative epidural local anaesthesia used, as preemptive blockade was not recognized at this time; however, 10/15 patients in the fentanyl group and 9/15 patients in the fentanyl $/ 0.1 \%$ bupivacaine group received intraoperative local anaesthesia in addition to the initial test dose (NS). Preemptive blockade was therefore not a factor in our findings. Lastly, before Dahl et al.'s work, ${ }^{3}$ the standard pain measurement had been to assess pain at rest, which was the method that those recommending the use of $0.1 \%$ bupivacaine had utilized. ${ }^{4,5}$ In fact, both Dahl et al.'s and Mourisse et al.'s studies ${ }^{3,6}$ utilized bupivacaine concentrations in excess of $0.1 \%$ which corroborates our recent work where $0.125 \%$ bupivacaine led to 
improved analgesia in postoperative abdominal surgery patients even at rest.?

We agree with Drs. Kehlet and Dahl that the addition of local anaesthetics to postoperative epidural opioids is advantageotus, when used in the appropriate concentrations.

N.H. Badner MD FRCPC

London, Ontario

REFERENCES

1 Badner NH. Komar WE. Bupivacaine 0.1\% does not improve postoperative epidural fentanyl analgesia after abdominal or thoracic surgery. Can J Anaesth 1992; 39: $330-6$.

2 Badner NH, Reimer EJ, Komar WE, et al. Low dose bupivacaine does not improve postoperative epidural analgesia in orthopedic patients. Anesth Analg 1991; 72: 337-41.

3 Dahl $J B$, Rosenberg $J$, Hansen $B L$, et al. Differential analgesic effects of low-dose epidural morphine and morphine-bupivacaine at rest and during mobilization after major abdominal surgery. Anesth Analg 1992; 74: 362-5.

4 Logas WG, El-Baz N, El-Ganzouri A. Continuous thoracic cpidural analgesia for postoperative pain relief following thoracotomy: a randomized prospective study. Anesthesiology 1987; 67: 787-9.

5 Cullen ML, Staren ED, El-Ganzouri A, et al. Continuous epidural infusions for analgesia after major abdominal operations: a randomized, prospective, double-blind study. Surgery 1985; $98: 718-28$.

6 Mourisse J, Hasenbas MAWM, Gielen MJM, et al. Epidural bupivacaine, sufentanil or the combination for postthoracotomy pain. Acta Anaesthesiol Scand 1992; 36: $70-4$.

7 Badner NH, Bhandari R, Komar WE, Ganapathy S. $0.125 \%$ bupivacaine - the optimum concentration for postoperative epidural fentanyl; analgesic effects. Can J Anaesth 1992; 39; A71.

\section{Polamedco endotracheal tubes}

To the editor:

I would like to draw the readers' attention to a potential hazard in the use of Polamedco brand endotracheal tubes with Laerdal self-inflating bags. The emergency paramedic service here in Edmonton uses this brand of tube (presumably because of their fitted stylettes) and there have been several incidents of inability to ventilate the lungs with them. By chance, I witnessed one of these.

An intubated and resuscitated cardiac arrest victim was brought into the Emergency Department at one of our hospitals. As I glanced in the room I was urgently summoned by the respiratory technician who was at that moment extubating the trachea and proceeding to ventilate the lungs by mask. He stated that he had, over the course of several minutes, become increasingly unable to ventilate the lungs yet could discover no cause. Later, after discussion with other staff, the mechanism became clear.

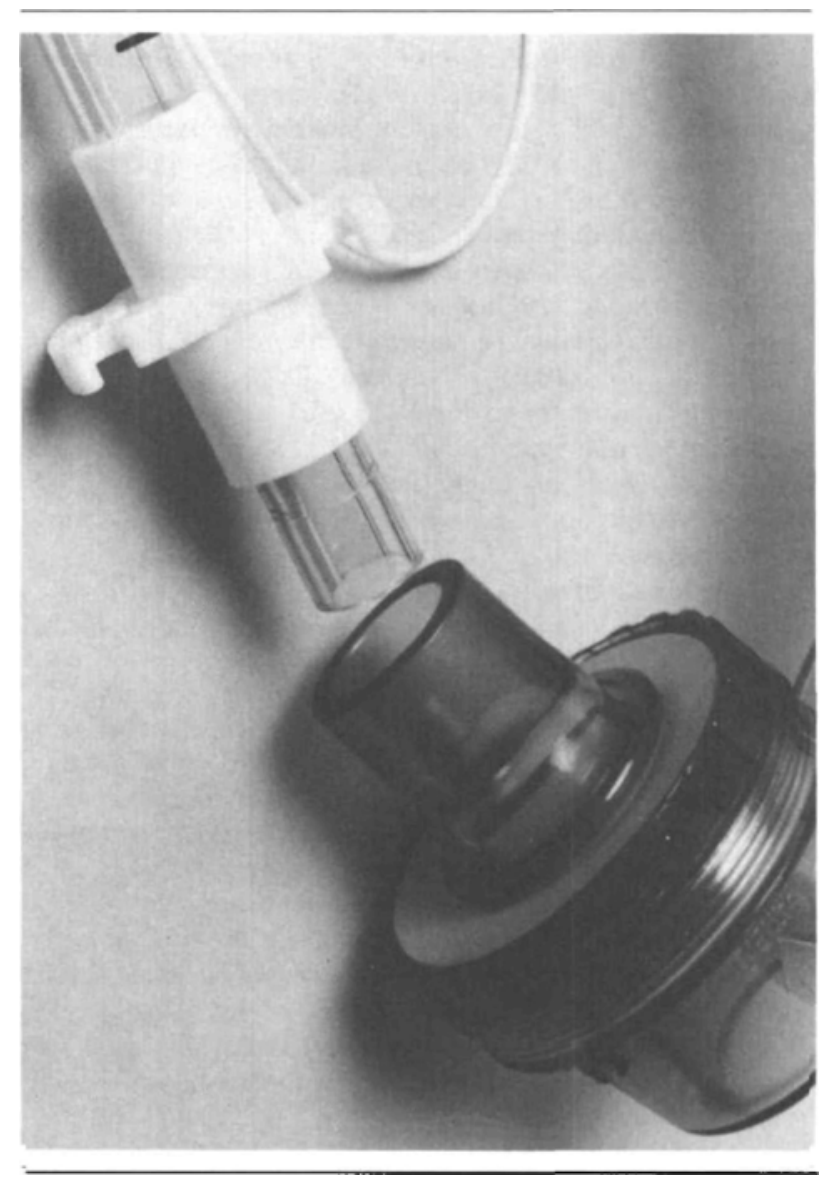

FIGURE Polamedco endotracheal tube and connection to Laerdal inflating bag.

The Polamedco endotracheal tube has an external connector which is fitted over the tube and is held in place by a small flange on the inside of the connector fitting into a crimp around the tube (Figure). With time, downward pressure, and lubrication by secretions, this fitting can slip. The endotracheal tube slides up through the connector and compresses the fish-mouth valve in the Laerdal bag, effectively preventing ventilation. It is extremely difficult to see this even if one knows what to look for.

This problem has arisen several times in our emergency departments and is starting to be appreciated by some of the casualty officers but seems to be relatively unknown amongst anaesthetists. It is important that we recognize this potential hazard early, especially when we receive patients who have been intubated in the lessthan-optimal pre-hospital environment.

\author{
K.R. McCaskill MD \\ University of Alberta Hospitals \\ Edmonton, Alberta
}

